\title{
Two overlooked Northern European species with a peculiar distribution correlated to the area of the Bölling-interstadial
}

\author{
Friedrich W. C. Mang
}

Am Knill 24, 2000 Hamburg 73, Germany

Two monomorphic species of Salix with a predominantly coastal distribution in Northern Europe have apparently been overlooked until now. Formerly, both species have occurred also in mires rich in lime, a habitat which is, however, rapidly vanishing.

A species from the Hastatae-group, usually classified as Salix hastata 'danica' Lange or S. hastata 'var. vegeta' And., is both morphologically and ecologically distinct from the arctic or alpine populations of the usually polymorphic Salix hastata L. Our taxon occurs exclusively in habitats rich in lime with a $\mathrm{pH} 7.2-7.9$. It grows to $1.2 \mathrm{~m}$ high but otherwise resembles the East-European-Asian Salix pyrolifolia Ledeb. as to bark, leaves, buds and catkins. Seedlings raised are remarkably uniform, and hybridisation experiments have produced only monomorphic progeny, so it might be possible that apomixis is operating. Büchler has shown that the chromosomes are $2 N=36$. The area of this species extends from Southern Sweden to the island of Amrum. There is a possibility that it may occur in the British Isles, perhaps classified under Salix malifolia Sm. It is remarkable that $\mathrm{H}$. Winslow, who collected in Sweden in the last century, applied this name to collections he made.

Material from Sweden, Denmark and Northern Germany has been revised in 1988 to 1990 , but the nomenclature remains unresolved. If this species really proves to be hitherto undescribed, the provisional name of Salix boellingiana Mang nom. prov. is here proposed in order to acknowledge the fact that the area coincides with that of the Bölling-interstadial, even if it still has to be ascertained how far the area of this species indicates such an ancient distribution pattern.

Another species with a similar area extending even further south to Hamburg is Salix $\times$ maritima Camus (Class. Saul. Europe (1904): 343 and Bull. Soc. Bot. France 1 (1903): 385). This taxon is close to Salix arenaria (L.) And. (=S. repens subsp. argentea $\mathrm{Sm}$.) but is distinct because of its stalked and leafed catkins, more crispate leaves with glands, larger stipules and distinct ridges on the wood. Because of the scarce material available to him, Camus classified it as a hybrid. The analysis of the progeny however produced only monomorphic forms. Probably this is a good species, but more information is needed.

\section{Habitat diversity and an unusually high hybrid frequency in willows at a Hamburg locality}

\author{
Friedrich W.C. Mang
}

Am Knill 24, D-2000 Hamburg 73, Germany

On clay terraces at Boberg near Hamburg, most willows found belong to hybrid complexes such as 